\title{
Nadir Bir Siliopati: Joubert Sendromu
}

\author{
A Rare Ciliopathy: Joubert Syndrome
}

Ayşe Yasemin ÇELIK', Deniz YILMAZ¹, Ayşegül Neşe ÇITAK KURT¹', Tülin HAKAN DEMIRKAN²

${ }^{1}$ Ankara Şehir Hastanesi, Çocuk Hastanesi, Çocuk Nöroloji Kliniği, Ankara, Türkiye

${ }^{2}$ Ankara Şehir Hastanesi, Radyoloji Kliniği, Ankara, Türkiye

\section{Öz}

Joubert sendromu anormal solunum paterni, hipotoni, ataksi, serebellar vermis hipoplazisi, gelişim geriliği, oküler anomaliler, renal kistler ve hepatik fibrozis ile karakterize otozomal resesif geçişli nadir bir siliopatidir. Kraniyal manyetik rezonans görüntüleme (MRG) bulgularında molar diş görünümü Joubert sendromunun tanısında önemli bir bulgudur. Joubert sendromunun karakteristik klinik ve radyolojik bulgularının farkında olunması erken tanı, uygun danışmanlık ve rehabilitasyona yardımcı olacaktır. Bu yazıda hipotoni ve anormal göz hareketleri ile hastanemize başvuran ve Joubert sendromu tanısı alan bir hasta sunulmuștur.

Anahtar Sözcükler: Joubert sendromu, Molar diş, Siliopati

\begin{abstract}
Joubert syndrome is a rare autosomal recessive ciliopathy characterized by abnormal breathing patterns, hypotonia, ataxia, cerebellar vermis hypoplasia, developmental delay, ocular abnormalities, renal cysts and hepatic fibrosis. Molar tooth appearance on cranial magnetic resonance imaging (MRI) is an important finding for the diagnosis of Joubert syndrome. Awareness of the characteristic clinical and radiological findings of the syndrome will allow early diagnosis, appropriate counseling and proper rehabilitation. A patient who admitted to our hospital with hypotonia and abnormal eye movements and was diagnosed with Joubert syndrome is presented.
\end{abstract}

Key Words: Joubert syndrome, Molar tooth, Ciliopathy

\section{GiRiş}

Joubert Sendromu (JS); hiperpne veya apne gibi anormal solunum paterni, anormal göz hareketleri, hipotoni, ataksi, gelişme geriliği, serebellum ve beyin sapının nöropatolojik anomalileri ile karakterize nadir otozomal resesif bir sendromdur (1). İlk kez 1969 yılında Marie Joubert tarafından tanımlanmıştır (2). Klasik JS, hipotoni, gelişme geriliği ve molar diş belirtisi olarak adlandırılan patognomonik serebellar ve beyin sapı malformasyonu ile karakterizedir (2). Son zamanlarda JS'nun nöroradyolojik özellikleri ve diğer sistem tutulumlarını tanımlamak için, Joubert Sendromuyla ilişkili bozukluklar terimi (JSRD) kabul görmüştür (2).Bu yazıda Joubert sendromu tanısı alan bir olgu eşliğinde literatür bilgileri gözden geçirilmiştir.

\section{OLGU SUNUMU}

Beş aylık kız hasta 6 günlükken fark edilen anormal göz ve baş hareketleri yakınması ile polikliniğimize getirildi. Öyküsünden 29 yaşındaki annenin ikinci gebeliğinden 37. gebelik haftasında normal vajinal yol ile 2380 gram doğduğu, doğum sonrası solunum sıkıntısı nedeniyle 4-5 saat kuvözde takip edildiği,
(10)

0000-0002-6734-0427: ÇELIK AY 0000-0002-0789-8955: YILMAZ D 0000-0002-7277-3550: KURT AN 0000-0003-0518-3013: HAKAN DEMIRKAN T
Çıkar Çatışması / Conflict of Interest: : Tüm yazarlar adına, ilgili yazar çıkar çatışması olmadığını belirtir. Finansal Destek / Financial Disclosure: Yazarlar bu olgu için finansal destek almadıklarını beyan etmişlerdir. Onay / Confirmation: Kayıt sırasında veliler tarafından araştırmaya katılım için bilgilendirilmiş bir onay imzalanmıştır.

Atıf yazım şekli / How to cite : Çelik AY, Yılmaz D, Kurt AN, Hakan Demirkan T. Nadir Bir Siliopati: Joubert Sendromu. Türkiye Çocuk Hast Derg 2022;16:336-338. 


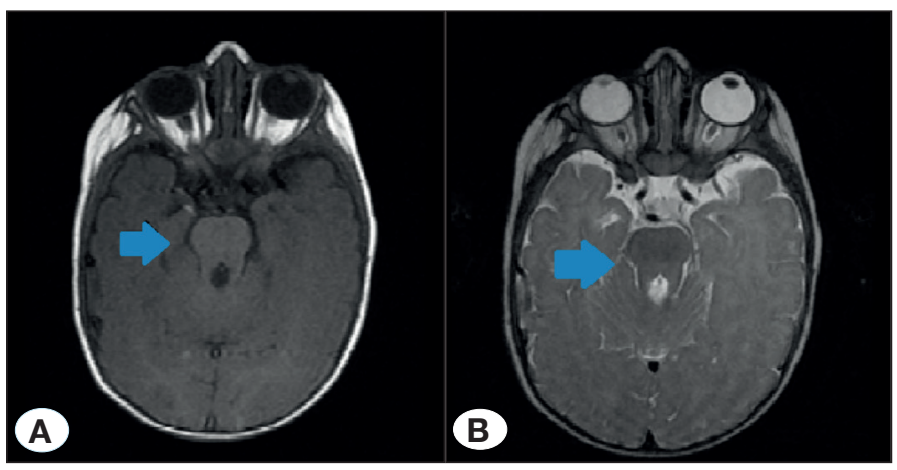

Resim 1: A ve B Aksiyal T1 ve T2 MRG kesitlerinde Joubert Sendromu için tipik molar diş görünümü.

indirekt hiperbilirubinemi nedeniyle bir gün fototerapi aldığı öğrenildi. Anne baba arasında akrabalık yoktu.

Fizik muayenede, baş çevresi 45 cm (50-75 p), vücut ağırlığı 8 kg (3-10 p), boyu 64 cm (10 p)'di. Nörolojik muayenesinde horizontal nistagmus ve aksiyel hipotonisi mevcut olan hastanın diğer sistem muayeneleri normaldi. Gelişimsel değerlendirmede, dil-bilișsel ve hareket işlevlerinde gerilik saptandı. Hastanın hemogram, tam biyokimya, kan gazı değerleri ve metabolik tetkikleri normaldi. Göz muayenesinde takip ve fiksasyonu yoktu, bilateral ekzotropya mevcuttu, göz dibi ise normal olarak değerlendirildi. Abdomen ultrasonografide (USG) böbrek ve karaciğerde anomali tespit edilmedi. Kraniyal Manyetik Rezonans Görüntülemede (MRG) posterior fossada vermis hipoplazisi, molar diş belirtisi olan hastada klinik ve radyolojik bulgularla JS düşünüldü (Resim $1 \mathrm{~A}$ ve B). Yapılan kromozomal mikrodizin analizi (Infinium ${ }^{\mathrm{TM}}$ CytoSNP-850K) normal olarak sonuçlandı. Fizik tedavi ve rehabilitasyon bölümünün önerileri de alınarak hastanın düzenli takibi planlandı.

\section{TARTIȘMA}

Otozomal resesif nadir bir hastalık olan JS'nun prevalansı 100.000'de birden daha azdır $(1,2)$. Siliopati olarak da bilinen primer silia disfonksiyonu, anormal genlerden kaynaklanır. Silialar; beyin, böbrekler, retina ve diğer organların ișleyișinde önemli bir bileşendir. Sillyogenezdeki bir kusur, çeșitli sinyal yollarının kesintiye uğramasına, JS ve JSRD'nin klinikopatolojik belirtilerine neden olur (2-4). Joubert sendromu radyolojik olarak molar diş belirtisi, hipotoni ve gelișme geriliği ile karakterizedir. Tüm klinik alt tiplerde okülomotor apraksi, nistagmus ve anormal solunum paterni görülebilir $(5,6)$. Ortalama tanı yaşı 33 aydır, bu da farklı klinik fenotiplere sahip sendromun tanısının yenidoğan döneminde zor olduğunu düşündürmektedir (2). Hastalar sıklıkla yașamın ilk aylarında hipotoni, anormal solunum paterni ve anormal göz hareketleri ile bașvururlar (2). Solunum anomalileri Pellegrino ve ark.(8) tarafından vakaların \%68'inde ve Kendall ve ark. tarafından vakaların \%44'ünde bildirilmiştir (7). Bizim hastamızın öyküsünde de doğum sonrası hipotonik olduğu ve solunum sıkıntısı nedeniyle yenidoğan yoğun bakım ünitesinde kısa süreli takip edildiği öğrenildi.

Joubert Sendromuna yol açan 40'a yakın gen literatürde tanımlanmışıı ve vakaların ancak \%50'sinde genetik kusur bulunabilmiştir. NPHP1, AH11, CEP290, RPGRIP1L, TMEM67, MKS3, ARL13B ve CC2D2A gibi genlerin patogenezde nedensel bir rol oynadığı bilinmektedir $(9,10)$. Hastamıza yapılan mikrodizin analizinde tüm tanımlı genlerin homozigot delesyonları dışlanmışıı. Moleküler tanısının konulması için ileri tetkikler planlanmıştır.

JSRD terimi, merkezi sinir sistemi dışındaki organ tutulumlarını tanımlamak için kullanılmaya başlamıştır $(1,11)$. JSRD orofasiyal dijital, retina, böbrek, okülorenal, karaciğer gibi organların tutulumuna bağlı olarak alt gruplara ayrlır (2). Hastamızda eșlik eden çoklu organ tutulumunun olmaması nedeniyle klasik JS tanısı düşünüldü.

JS'de konjenital hepatik fibroz, yüksek oranda retinal distrofiye eșlik eden polikistik böbrek hastalı̆̆ı, nefronoftizi, polidaktili ve küçük göğüs kafesi gibi iskelet anomalileri bulunabilir (12). Anormal göz hareketleri, altta yatan okülomotor disfonksiyona bağlı olarak ortaya çıkar ve okülomotor apraksi \% 80 oranında en karakteristik ve en sık görülen göz bulgusudur. Nistagmus $\% 72$, strabismus $\% 74$, pitozis $\% 43$ ve retina dejenerasyonu $\%$ 38 oranında bulunan diğer göz bulgularıdır $(2,10)$. Hastamızda da göz bulgusu olarak horizontal nistagmus mevcuttu.

Temel radyolojik bulgular; vermisin tam veya parsiyel yokluğu, hipoplastik serebeller pedinküller ve buna bağlı 4. ventrikül deformitesidir. Bu bulgular aksiyal MRG'de 'molar diş' görünümüne neden olur (5). Serebeller hemisferler ve serebrum genellikle normaldir. Ancak; \%6- 20 oranında korpus kallosum agenezi ve disgenezisine bağı lateral ventriküllerde hafif derecede genișleme izlenebilir $(3,13)$. Ayrıca konjenital malformasyonlar, hipotalamik hamartom ve nadiren hipofiz bezinin yokluğu eşlik edebilir (3).

Anormal solunum paterni, apnesi olan hastalarda havayolu obstrüksiyonlarını (hipotonik hava yolu, hipertrofik tonsiller) beyin sapı disregülasyonundan ayırt etmek için polisomnogram yapılabilir. Oküler incelemeler görme keskinliği, yarık lamba muayenesi, fundus ve elektroretinogram (retinal distrofi varlığında) değerlendirilmesini içerir. Standart idrar tetkiki ve idrar konsantrasyonu değerlendirilmelidir (3). İnfantların çoğunda kistik böbrek hastalığı ve karaciğer fibrozisi gelișmeyeceğinden takip sürecinde abdomen USG periyodik olarak tekrarlanmalıdır (7).

Tedavi genellikle destekleyicidir ve multidisipliner bir yaklaşım içerir. Anormal solunum paterni olan hastalar apne açısından takip edilmeli ve klinik gerekliliğe göre yenidoğan döneminde kafein gibi uyarıcı ilaçlar, oksijen desteği, ciddi solunum yetmezliği olanlarda mekanik destek ve/veya trakeostomi düșünülebilir. Şiddetli disfajisi olan çocuklarda beslenme için nazogastrik beslenme tüpleri veya gastrostomi tüpü yerleștirilebilir. Nöbet 
varlığında antiepileptik ilaçlarla tedavi edilmelidir. Polidaktili için düzeltici cerrahi yapılabilir (7). Bilişsel zorluklar, uygun rehabilitasyon stratejisi ve düzenli takip gerektirir. Prognoz, organ tutulumunun türüne ve yaygınlığına bağlıdır (3).

Klinik heterojenite JS tanısını zorlaştırmaktadır bu nedenle sendroma özgü radyolojik bulgular eşliğinde anormal solunum paterni, hipotonisite, anormal göz hareketleri olan hastalarda akılda tutulmalı ve sonradan ortaya çıkabilecek komplikasyonlar açısından multidisipliner düzenli izlem gerektiği unutulmamalıdır.

\section{KAYNAKLAR}

1. Kumar P, Dey A, Mittal K, Sharma R, Goyal A, Hira P. Joubert syndrome: A classic case. J Family Med Prim Care 2019;8:311-2

2. Akhtar A, Hassan SA, Falah NU, Khan M, Sheikh FN. Joubert Syndrome: A Rare Radiolo-gical Case. Cureus 2019 Dec 18;11:e6410.

3. Brancati F, Dallapiccola B, Valente EM. Joubert Syndrome and related disorders. Orphanet J Rare Dis 2010;5:20.

4. Shaik L, Ravalani A, Nelekar S, Gorijala VK, Shah K. Joubert Syndrome: A Molar Tooth Sign in Disguise. Cureus 2020;12:e9718.

5. Akcakus M, Gunes T, Kumandas S, Kurtoglu S, Coskun A. Joubert syndrome: Report of a neonatal case. Paediatr Child Health 2003;8:499-502.
6. Parisi M, Glass I. Joubert Syndrome. 2003 Jul 9 [updated 2017 Jun 29]. In: Adam MP, Ar-dinger HH, Pagon RA, Wallace SE, Bean LJH, Stephens K, et al. editors. GeneRe-views ${ }^{\circledR}$ [Internet]. Seattle (WA): University of Washington, Seattle; 1993-2020.

7. Pellegrino JE, Lensch MW, Muenke M, Chance PF. Clinical and molecular analysis in Jou-bert syndrome. Am J Med Genet 1997;72:59-62.

8. Kendall B, Kingsley D, Lambert SR, Taylor D, Finn P. Joubert syndrome: a clinico-radiological study. Neuroradiology. 1990;31(6):502-506.

9. Salva I, Albuquerque C, Moreira A, Dâmaso C. Nystagmus in a newborn: a manifestation of Joubert syndrome in the neonatal period. BMJ Case Rep 2016;2016:bcr2015213127.

10. Wang SF, Kowal TJ, Ning K, Koo EB, Wu AY, Mahajan VB, et al. Review of Ocular Mani-festations of Joubert Syndrome. Genes (Basel) 2018;9:605.

11. Elhassanien AF, Alghaiaty HA. Joubert syndrome: Clinical and radiological characteristics of nine patients. Ann Indian Acad Neurol 2013;16:239-44.

12. Parisi MA. The molecular genetics of Joubert syndrome and related ciliopathies: The challenges of genetic and phenotypic heterogeneity. Transl Sci Rare Dis 2019;4:25-49.

13. Bin Dahman HA, Bin Mubaireek AH, Alhaddad ZH. Joubert syndrome in a neonate: case re-port with literature review. Sudan J Paediatr 2016;16:53-7. 